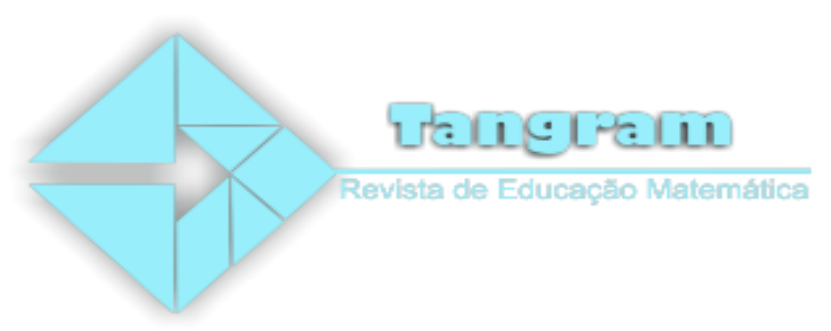

\title{
A Matemática Financeira e Educação Financeira: impactos na formação inicial do professor
}

\section{Financial Mathematics And Financial Education: impacts in initial teacher training}

\author{
Adriana Stefanello Somavilla ${ }^{1}$ \\ Evandro Carlos Andretti ${ }^{2}$ \\ Tania Stella Bassoi ${ }^{3}$
}

\begin{abstract}
Resumo: A pesquisa em questão apresenta alguns aspectos sobre a presença da disciplina de Matemática no curso de Licenciatura em Matemática da Universidade Estadual do Oeste do Paraná de Cascavel/PR. Com uma abordagem qualitativa de cunho fenomenológico, esse estudo integra o Projeto de Pesquisa: "A Matemática Financeira e a Educação Financeira no contexto educacional: um olhar para a formação de professores de Matemática", que é desenvolvido no Instituto Federal do Paraná (IFPR) de Foz do Iguaçu/PR. Nesse sentido, considera-se que o desenvolvimento de competências no processo de formação inicial de um docente de matemática pode ser favorecido por movimentos colaborativos entre as instâncias de ensino: a Educação Superior e a Educação Básica. Além disso, o estudo faz considerações sobre as temáticas matemática financeira e educação financeira e pretende colaborar para um repensar sobre a formação financeira em todos os níveis de ensino, assim como para os cidadãos em geral.
\end{abstract}

Palavras-chave: Matemática Financeira. Educação Financeira. Licenciatura em Matemática.

Abstract: The research in question presents some aspects abole the presence of Mathematics in the Mathematics Degree course of the State University of the Western of Paraná in Cascavel/PR. With a qualitative approach of a fenomenologia nature, this study integrates the Research Project: "Financial Mathematics and Financial Education in the educational context: a look at the training of Mathematics teachers", which is developed at the Federal Institute of Paraná (IFPR) in Foz do Iguaçu / PR. In this sense, it is considered that the development of competences in the process of initial formation of a mathematics teacher can be favored by collaborative movements between the instances of teaching: Higher Education and Basic Education. In addition, the study makes considerations on the topics financial

\footnotetext{
1 Docente de Matemática do Ensino Básico, Técnico e Tecnológico do Instituto Federal do Paraná (IFPR)/Campus Foz do Iguaçu/PR. E-mail: adriana.soma@ifpr.edu.br

${ }^{2}$ Mestre em Ensino e Licenciado em Matemática pela Universidade Estadual do Oeste do Paraná - UNIOESTE. Professor da Faculdade União das Américas - UNIAMÉRICA. E-mail: evandroandretti@gmail.com

${ }^{3}$ Professora do Programa de Pós-graduação em Educação em Ciências e Educação Matemática - Nível Doutorado da Universidade Estadual do Oeste do Paraná (UNIOESTE)/ Campus de Cascavel/PR. Professora adjunta da Universidade Estadual do Oeste do Paraná, do colegiado de Matemática do campus de Cascavel/PR.E-mail: tstellabassoi@gmail.com
}

Tangram - Revista de Educação Matemática, Dourados - MS - v.2 n1. , pp. 102 - 121 (2018) 


\section{A Matemática financeira e Educação Financeira: impactos na formação inicial do professor}

mathematics and financial Education and aims to collaborate in a rethinking of financial education at all levels of education, as well as for citizens in general.

Keywords: Financial math. Financial education. Degree in Mathematics.

\section{Introdução}

Há um consenso dos pesquisadores e professores de todas as áreas sobre a importância da Matemática Financeira para a vida das pessoas. Do mesmo modo, mundialmente, iniciativas e perspectivas que visam elevar o nível de literacia financeira dos cidadãos têm sido promovidas. A Organização para a Cooperação e Desenvolvimento Econômico (OCDE) é uma das responsáveis pela orientação aos diversos países sobre essa questão, com o olhar para a Educação Financeira e sua inserção na escola básica, como uma forma de disseminar, desde cedo uma cultura financeira satisfatória.

De acordo com Somavilla (2017, p. 65), “[...] as leis educacionais orientam as pessoas e a sociedade sobre seus direitos. Uma lei não modifica uma realidade, mas aponta caminhos." Dessa forma, tanto na Lei de Diretrizes e Bases da Educação Nacional - Lei no 9.394, de 20 de dezembro de 1996, quanto nos Parâmetros Curriculares Nacionais (PCN), a questão da educação para a cidadania é evidenciada. Nessa direção, os PCN para o ensino fundamental, Terceiro e Quarto Ciclos (1998, p.5) sugerem o papel da educação no desenvolvimento das pessoas para o novo milênio e direciona para a necessidade de construir uma escola voltada para a formação dos cidadãos.

Nessa perspectiva e no que se refere ao ensino de Matemática, deve possibilitar ao aluno compreender sua realidade, e como consta em Brasil (1998, p. 60), desenvolver suas "[...] capacidades cognitivas e sua confiança para enfrentar desafios, de modo a ampliar os recursos necessários para o exercício da cidadania, ao longo de seu processo de aprendizagem.” Já nas Diretrizes Curriculares de Matemática para a Educação Básica do Estado do Paraná, as orientações evidenciam os conhecimentos sobre a matemática financeira.

\footnotetext{
É importante que o aluno do Ensino Médio compreenda a matemática financeira aplicada aos diversos ramos da atividade humana e sua influência nas decisões de ordem pessoal e social. Tal importância relaciona-se o trato com dívidas, com crediários à interpretação de descontos, à compreensão dos reajustes salariais, à escolha de aplicações financeiras, entre outras. (Paraná, 2008, p. 61)
}

Nesse contexto, alguns autores entendem que o ensino da matemática financeira e educação financeira estão entrelaçados, abrindo assim as portas para a cidadania plena.

Tangram - Revista de Educação Matemática, Dourados - MS - v2 n. 1, pp. 102 - 121 (2018) 


\section{A Matemática financeira e Educação Financeira: impactos na formação inicial do professor}

Segundo Silva (2011) “[...] queremos educar financeiramente nossos alunos, como parte de uma educação matemática, concebida como uma educação pela matemática e não uma educação para a matemática. (Silva, 2011, apud Losano, 2013, p. 48). Ainda em tempo, sobre a associação das temáticas matemática financeira e educação financeira, apresenta-se ainda um cenário diverso e confuso. Somavilla (2017) apresenta uma análise feita de uma das 13 categorias apresentadas por Almeida e Junior (2015), resultantes do mapeamento de 47 pesquisas referentes à temática Educação Matemática Financeira Escolar no período de 1999 a 2015.

Observa-se nesse estudo que as categorias explicitadas estão voltadas para a Educação Financeira, embora ao analisar as pesquisas pertencentes a cada categoria, percebe-se a presença da Matemática Financeira em muitas delas. (Somavilla, 2017, p. 62)

Assim a categoria escolhida aleatoriamente "Aspectos Epistemológicos do Uso da Educação Financeira na Formação Inicial" apresentou 3 pesquisas relacionadas por Almeida e Junior (2015). Na análise das 3 pesquisas apresentadas pelos autores, Somavilla (2017, p.64) expõe que há “[...] dificuldades dos próprios pesquisadores, professores e estudiosos da Matemática Financeira e da Educação Financeira em estabelecer relações entre os termos".

De um modo geral, as pesquisas sobre formação de professores aumentaram nos últimos anos, tendo como temas centrais estudos sobre os processos formativos vivenciados por docentes e a definição dos tipos e da natureza dos seus saberes. Percebe-se um esforço crescente dos pesquisadores em mapear problemáticas da formação docente. A evolução da pesquisa no campo das ciências da educação reflete propostas atuais e mudanças no âmbito da formação de professores.

Tendo esse olhar, o estudo analítico qualitativo de cunho fenomenológico em questão foi delineado pela interrogação de pesquisa: O que revela sobre a presença da disciplina de Matemática Financeira no curso de Licenciatura em Matemática na Universidade Estadual do Oeste do Paraná, de Cascavel/PR? Nessa direção, se alinham alguns aspectos sobre a literacia financeira dos professores de Matemática e dos cidadãos de uma forma geral, o formato dos cursos de formação inicial de professores de Matemática nessa perspectiva e alguns apontamentos sobre a conexão entre a matemática financeira e educação financeira.

Por fim, esse trabalho busca promover reflexões sobre a Matemática Financeira e Educação Financeira. Entende-se que apesar das temáticas serem discutidas mundialmente

Tangram - Revista de Educação Matemática, Dourados - MS - v2 n. 1, pp. 102 - 121 (2018) 


\section{A Matemática financeira e Educação Financeira: impactos na formação inicial do professor}

e tenham relevância social-econômica, vários questões concernentes às temáticas ainda não são discutidas no contexto escolar.

\section{Os professores de matemática e o contexto da literacia financeira}

As questões referentes ao letramento financeiro das pessoas normalmente são pautas de eventos associados ao slogan "Cidadania Financeira". A cidadania financeira é um conceito relativo aos direitos e deveres do cidadão quando o assunto é sua vida financeira. Esse campo tem como foco três eixos principais: gestão financeira pessoal, relacionamento do Sistema Financeiro Nacional (SFN) com o cidadão e o relacionamento das instituições financeiras com o cidadão.

Os termos educação, proteção e inclusão financeira estão associados a cidadania financeira e nessa direção, de acordo com Brasil (2017, p.19) na Série Cidadania Financeira, as questões relativas a educação financeira e ao conhecimento em finanças básicas “[...] quando combinado com habilidade em aritmética, tende a auxiliar as pessoas a reagirem de maneira autônoma a eventos que refletem no seu bem-estar financeiro." Nesse mesmo documento é apresentada uma pesquisa aplicada em 2015, pelo Banco Central em parceria com a Serasa Experian e o Ibope e baseada no Toolkit da Infe/OCDE, com o objetivo de verificar o nível de educação financeira da população brasileira.

Com relação à dimensão Conhecimento, no geral, os respondentes obtiveram um percentual maior de erros em questões relacionadas à matemática financeira - juros simples e compostos, valor do dinheiro no tempo e juros pagos em empréstimos. Com relação à análise por sexo, as diferenças estatisticamente significativas foram as de conhecimento matemático e lógico, com um percentual de acerto menor para as mulheres. (BCB, 2017, p. 55)

Nesse sentido, a sociedade de uma forma geral acredita que quando o assunto é dinheiro o ensinamento deve vir da família. E essa ideia herdada impacta diretamente nas políticas públicas voltadas a uma formação financeira em todos os níveis de ensino. Já sobre a relação entre uma formação financeira e a formação inicial de professores, Somavilla e Bassoi (2017, p. 42) entendem que

[...] pensar criticamente a formação inicial de professores é também pensar numa formação de professores para uma escola cidadã. Embora pareça "ampla" a ideia de cidadania, a educação é um processo que promove a participação dos indivíduos e projeta para futuras gerações competências e saberes necessários para uma formação financeira equilibrada.

Tangram - Revista de Educação Matemática, Dourados - MS - v2 n. 1, pp. 102 - 121 (2018) 


\section{A Matemática financeira e Educação Financeira: impactos na formação inicial do professor}

As autoras verificaram também em sua pesquisa que a maior parte dos professores de Matemática entrevistados tiveram a disciplina de Matemática Financeira em sua formação inicial, fato esse que não foi decisivo para a inserção dessa disciplina nos cursos de Licenciatura em Matemática participantes da pesquisa. Assim, Somavilla e Bassoi (2017, p.77) questionam a maneira com que fora ministrada essa disciplina nos cursos de Licenciatura em Matemática: "[...] talvez tenha sido conduzida com maior ênfase ao "purismo" matemático e menos ênfase a sua contribuição para melhorar o nível de literacia financeira dos futuros acadêmicos e da população."

Ainda em tempo, mesmo que os estudos educacionais apresentem uma grande variedade de opções teórico-metodológicas, esses têm indicado que a formação docente ocorre de forma contínua, começando até mesmo antes da formação inicial docente e continuando durante toda a vida profissional.

O desenvolvimento profissional dos professores é objetivo de propostas educacionais que valorizam sua formação não mais baseada na racionalidade técnica, que os considera meros executores de decisões alheias, mas em uma perspectiva que reconhece sua capacidade de decidir (Pimenta e Lima, 2004, p. 13).

Diante disso, existe uma fragilidade quando o assunto é o contexto da literacia financeira dos professores de Matemática. Não há consenso entre os pesquisadores e docentes dessa área sobre a inserção da disciplina de Matemática Financeira ou da Educação Financeira (ou de ambas) nos cursos de Licenciatura em Matemática.

\section{Caminho percorrido na investigação}

Esse estudo integra o Projeto de Pesquisa intitulado "A Matemática Financeira e a Educação Financeira no contexto educacional: um olhar para a formação de professores de Matemática", desenvolvido no Instituto Federal do Paraná (IFPR), no campus de Foz do Iguaçu/PR. Ao adotar uma postura analítica de pesquisa de cunho fenomenológico, os passos metodológicos foram sendo delineados pela interrogação de pesquisa: $O$ que revela sobre $a$ presença da disciplina de Matemática Financeira no curso de Licenciatura em Matemática na Universidade Estadual do Oeste do Paraná, de Cascavel/PR?

Nessa perspectiva, um dos princípios básicos da fenomenologia é a intencionalidade. Martins e Bicudo (1983, p. 10) entendem que ela

Tangram - Revista de Educação Matemática, Dourados - MS - v2 n. 1, pp. 102 - 121 (2018) 


\section{A Matemática financeira e Educação Financeira: impactos na formação inicial do professor}

[...] procura abordar o fenômeno, aquilo que se manifesta por si mesmo, de modo que não o parcializa ou o explica a partir de conceitos prévios, de crenças ou de afirmações sobre o mesmo, enfim, um referencial teórico. A intenção da fenomenologia é abordar o fenômeno diretamente, interrogando-o, tentando descrevê-lo e procurando captar sua essência.

Mutti e Somavilla (2017, p.1) expõem que

[...] assumir a postura fenomenológica de investigação significa ser orientado por uma interrogação, disparada por um desacerto; pelo interesse em trazer à luz aspectos do fenômeno focado que se mostram ainda obscuros para aquele que o interroga, a saber, o pesquisador.

Dessa forma, identificaram-se como sujeitos significativos dessa investigação os professores do curso de Licenciatura em Matemática que ministraram a disciplina de Matemática Financeira na Unioeste de Cascavel/PR. Também se considerou relevante, olhar para os Planos de Ensino (inicialmente denominados Programas de Disciplina) referentes à disciplina de Matemática Financeira ministrada no curso de Licenciatura em Matemática.

Nesse rumo, foi elaborado um roteiro de entrevista com o foco nos depoimentos e manifestações espontâneas dos sujeitos significativos para a pesquisa, e na sequência foi realizada a entrevista e a transcrição das mesmas. E ainda, nesse estudo de cunho fenomenológico, além de uma atitude de abertura ao que se "mostra", novas possibilidades de compreensões na trajetória metodológica fizeram parte do processo de investigação. Sendo assim, não foram estabelecidos objetivos a priori, pois não houve esgotamento das possíveis manifestações do fenômeno.

Desse modo, tendo como instrumento de análise de pesquisa o software Atlas $\mathrm{ti}^{4}$, foram inseridos os Planos de Ensino obtidos na Universidade Estadual do Oeste do Paraná (UNIOESTE)/Campus de Cascavel/PR, vigentes no curso de Licenciatura em Matemática no período de 1989 à 2017, além das entrevistas transcritas P1 e P2, realizadas com os docentes dessa Instituição que ministraram a disciplina de Matemática Financeira no período citado, como mostra a Figura 1.

\footnotetext{
${ }^{4}$ Obteve-se a licença do software Atlas ti.

Tangram - Revista de Educação Matemática, Dourados - MS - v2 n. 1, pp. 102 - 121 (2018)
} 
A Matemática financeira e Educação Financeira: impactos na formação inicial do professor

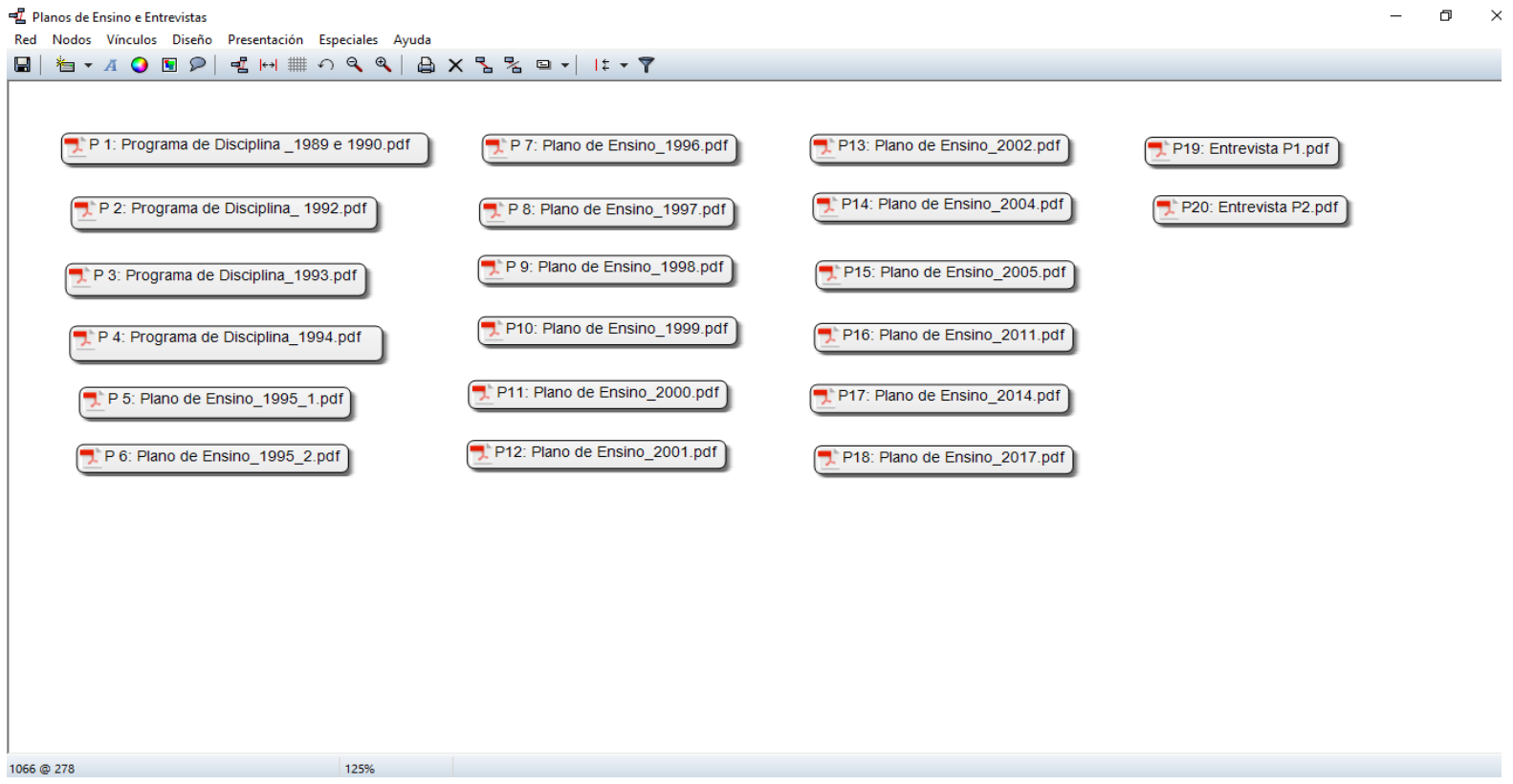

Figura 1: Planos de Ensino e Entrevistas

Fonte: Elaborado pelos autores

Dando prosseguimento à investigação, após a inserção e leitura dos documentos primários, foram destacadas as unidades de significado, com o olhar vigilante para a interrogação de pesquisa: $O$ que revela sobre a presença da disciplina de Matemática Financeira no curso de Licenciatura em Matemática na Universidade Estadual do Oeste do Paraná, de Cascavel/PR?

Diante da trajetória metodológica adotada, as categorias abertas ${ }^{5}$ foram sendo construídas e se modificando conforme o contexto da pesquisa. Já o ato de reduzir ou epoché considera-se a atitude fenomenológica que o pesquisador tem quando busca as conexões entre as unidades de significado na formação das categorias. Portanto, após salientar as unidades de significado nos Planos de Ensino e entrevistas dos docentes, buscou-se pelas convergências entre elas, surgindo assim as categorias abertas explicitadas na Figura 2.

5 São denominadas categorias abertas aquelas que permitem várias interpretações.

Tangram - Revista de Educação Matemática, Dourados - MS - v2 n. 1, pp. 102 - 121 (2018) 
A Matemática financeira e Educação Financeira: impactos na formação inicial do professor

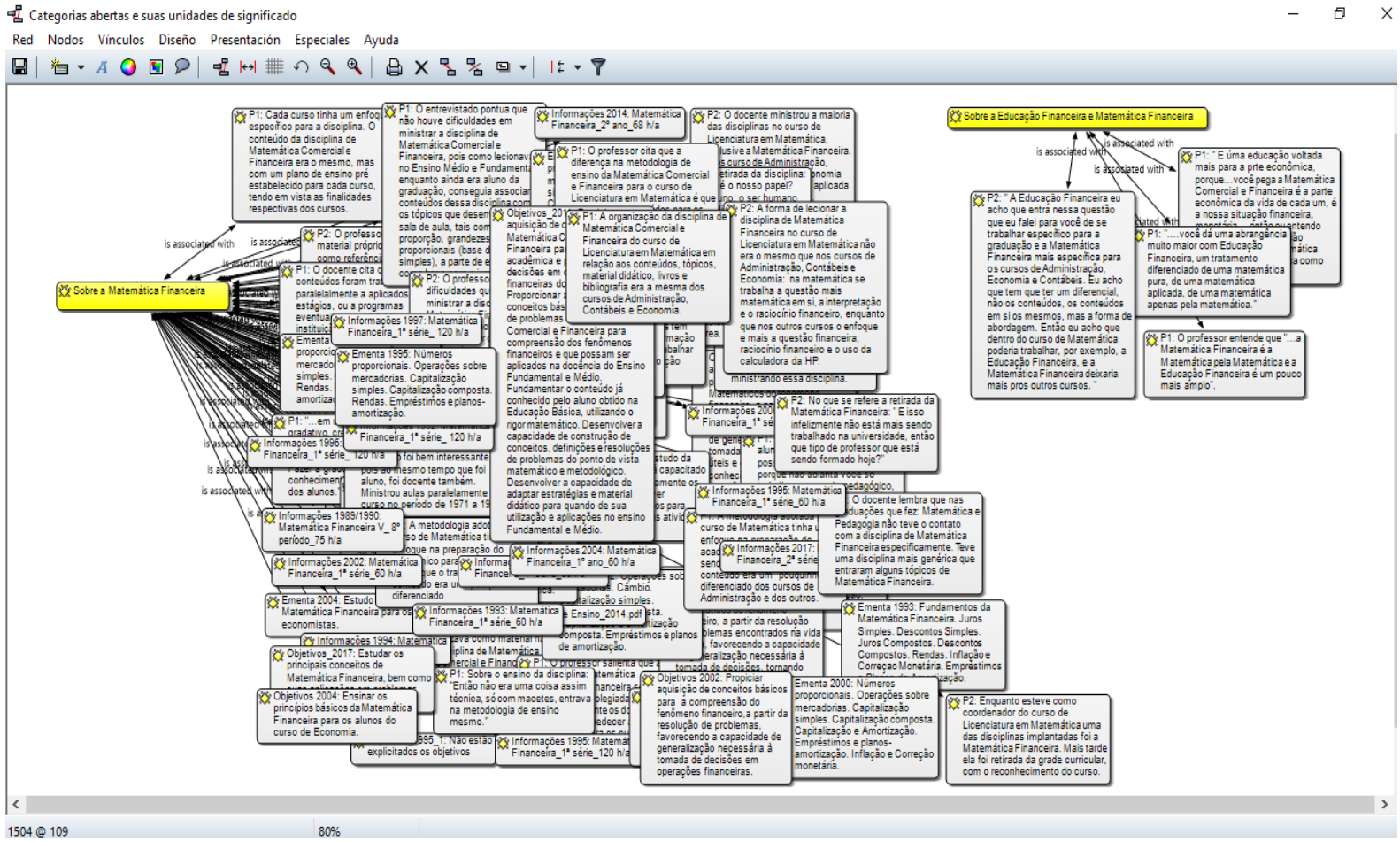

Figura 2: Categorias abertas e suas unidades de significado

Fonte: Elaborado pelos autores

Por fim, cada categoria aberta e suas unidades de significado foram descritas e na sequência, apresentadas as interpretações conforme exposto no próximo item.

\section{Breve descrição e interpretação das categorias}

Quando um estudo é delineado por uma interrogação de pesquisa, a compreensão do mundo que é apresentado pelo outro exige a suspensão de crenças e conceitos nele préestabelecidos. Segundo Masini (1982, p.36), o método fenomenológico hermenêutico exige uma reflexão constante e um exercício longo e minucioso na identificação das referências qualitativamente significativas que surgem na pesquisa. Nesse sentido, estão citados alguns códigos ${ }^{6}$ considerados pelos pesquisadores relevantes à análise dos dados e referem-se às unidades de significado destacadas nos documentos inseridos do software Atlas.ti. Nos itens a seguir, estão as descrições seguidas da interpretação, à luz da interrogação de pesquisa exposta anteriormente.

\footnotetext{
${ }^{6}$ Utiliza-se o código 23:2 por exemplo, para indicar a segunda unidade destacada do vigésimo terceiro documento primário inserido no software Atlas.ti.
}

Tangram - Revista de Educação Matemática, Dourados - MS - v2 n. 1, pp. 102 - 121 (2018) 


\section{A Matemática financeira e Educação Financeira: impactos na formação inicial do professor}

\section{Categoria 1: Sobre a Matemática Financeira}

Nessa categoria as unidades de significado destacadas nos Planos de Ensino disponibilizados pela Instituição, indicam a presença da disciplina de Matemática Financeira no curso de Licenciatura em Matemática da UNIOESTE de Cascavel/PR, no período de 1989 à 2017. Ela esteve presente no rol das disciplinas obrigatórias do curso de Licenciatura em Matemática no período citado. Houve alternâncias de cargas horárias de 60 h/a e 120 h/a anuais, embora tenha a manutenção na maioria dos anos a carga horária de 60 h/a para o período letivo anual. Foi denominada de Matemática Financeira, com exceção no ano de 2011, que chamou-se a disciplina de Matemática Comercial e Financeira. Outro ponto observado é que a disciplina foi ofertada na maioria das vezes no $1^{\circ}$ ano letivo do curso de Licenciatura em Matemática.

Quanto as ementas verificados nos Planos de Ensino, na maioria delas consta: "Números proporcionais. Operações sobre mercadorias. Capitalização simples. Capitalização composta. Rendas. Empréstimos e planos de amortização. Inflação e correção monetária" $(11: 2)^{7}$.

Já ao analisar os objetivos elencados nos Planos de Ensino, destaca-se na maioria dos planos o seguinte: “Propiciar aquisição de conceitos básicos para o entendimento dos aspectos matemáticos do fenômenos financeiro, a partir da resolução de problemas encontrados na vida prática, favorecendo a capacidade de generalização necessária à tomada de decisões, tornando úteis e operacionáveis os conhecimentos para solução de questões financeiras." (13:3). Atenta-se para um dos objetivos enunciado: "Ensinar os princípios básicos de Matemática Financeira para os alunos do curso de Economia” (14:3).

Ao olhar para os relatos dos docentes, observou-se algumas convergências quanto a metodologia adotada no ensino da Matemática Financeira para o curso de Licenciatura em Matemática ser diferenciada dos cursos de Administração, Ciências Contábeis e Ciências Econômicas. Também confirmam que os Planos de Ensino, ementas, referências bibliográficas são praticamente iguais para a disciplina em questão, destacando que o enfoque e as modificações ocorrem conforme objetivos de cada curso. Outro ponto salientado pelos professores é que a oferta da disciplina de Matemática Financeira foi

\footnotetext{
${ }^{7}$ Utiliza-se o código 11:2 para indicar a segunda unidade destacada do décimo primeiro documento primária inserido no software Atlas ti.
}

Tangram - Revista de Educação Matemática, Dourados - MS - v2 n. 1, pp. 102 - 121 (2018) 


\section{A Matemática financeira e Educação Financeira: impactos na formação inicial do professor}

ministrada separadamente para cada curso, o que favoreceu o formato de uma metodologia de ensino e didática diferenciadas.

Nessa direção, os depoimentos dos docentes divergem quanto a relevância da Matemática Financeira como disciplina no curso de Licenciatura em Matemática. Num dos relatos o docente explica que não teve opção na escolha de ministrar a disciplina de Matemática Financeira: "Na verdade foi assim... uma necessidade né? "Porque a minha formação... mais acadêmica era na área de Geometria Analítica, eu me especializei em Geometria Analítica, aí por necessidade eu assumi a disciplina de Matemática Comercial e Financeira” (19:6). Manifesta também sua posição sobre não ser necessária a inserção da disciplina em questão no curso de Licenciatura em Matemática: "E a Matemática tem que ter uma matemática mais exata, mais aprofundada, porque esses conteúdos o aluno consegue aprender por si só né? Que é importante é importante. Pode ser dado na Metodologia e na Didática da Matemática? Pode! Pode ser trabalhado paralelamente? Pode!” (19:21)

Já noutro relato em que o docente afirma ter escolhido ministrar a disciplina de Matemática Financeira na sua vida profissional, faz um discurso de valorização da disciplina para a vida das pessoas: “...eu acho que a Matemática financeira você usa todo dia, toda hora você está usando Matemática Financeira, ou seja, todo professor que vai para uma sala de aula tem que trabalhar Matemática Financeira. De uma forma ou de outra está lá, dentro da programação a nível de estado está lá Matemática Financeira embutida dentro de PA, de PG, dentro de Logaritmo, de exponencial, dentro de funções... então você pode pegar qualquer livro de ensino médio e tá lá Matemática Financeira está presente e isso tem que ser trabalhado e infelizmente os nossos professores não estão sendo preparados para isso, um dos motivos foi... porque não tá saindo preparado?” (20:5)

Nesse rumo, pela descrição acima, observam-se vários aspectos que circundam a temática Matemática Financeira. Pelos Planos de Ensino observa-se que a ementa predominante no período analisado foi "Números proporcionais. Operações sobre mercadorias. Capitalização simples. Capitalização composta. Rendas. Empréstimos e planos de amortização. Inflação e correção monetária" $(11: 2)^{8}$. Essa ementa ficaria melhor denominada como 'Matemática Financeira e Comercial', pois mantém tópicos que a

\footnotetext{
${ }^{8}$ Utiliza-se o código 11:2 para indicar a segunda unidade destacada do décimo primeiro documento primária inserido no software Atlas ti.

Tangram - Revista de Educação Matemática, Dourados - MS - v2 n. 1, pp. 102 - 121 (2018)
} 


\section{A Matemática financeira e Educação Financeira: impactos na formação inicial do professor}

representam, tal como “Operações sobre mercadorias". Pela unidade de significado verificase que em 2011 a disciplina denominou-se dessa forma. Porém essa modificação foi isoladamente feita somente nesse ano. Esse fato pode ter haver com a questão dos docentes entrevistados assumirem a disciplina nos diversos cursos citados anteriormente e adotarem material didático (apostilas) elaborados por eles.

Ainda em tempo, surge num depoimento: "Em Ciências Contábeis, Administração e Ciências Econômicas a gente era mais genérico, era usado uma calculadora científica, uma calculadora financeira e livro específico pra isso. Agora para o curso de Matemática eram trabalhados os conteúdos de uma forma mais...de forma assim...que ele pudesse ser um docente, o envolvimento do conteúdo com o aluno do curso de Matemática era mais na preparação dele como professor, como docente, então o conteúdo era um pouquinho diferenciado, o tratamento que se dava ao conteúdo." (19:10). Essa fala é controversa com o que se mostrou nessa pesquisa, pois é equivocada quando se anuncia a utilização de livro específico para os cursos, sendo que os entrevistados adotaram apostilas elaboradas por eles mesmos. Embora seja reforçada nos relatos a questão da metodologia de ensino e didática nas aulas de Matemática Financeira ser diferenciada entre os cursos, observa-se que um dos objetivos do Plano de Ensino do curso de Licenciatura em Matemática traduz incerteza quando explicita: "Ensinar os princípios básicos de Matemática Financeira para os alunos do curso de Economia" (14:3).

O cenário encontrado nesse estudo e de uma forma geral sobre a presença ou não da Matemática Financeira nos cursos de formação inicial de um professor de matemática sugere que os entendimentos pessoais dos docentes sobre uma formação financeira impactam também a elaboração dos Projetos Pedagógicos dos Cursos (PPC). Somavilla e Bassoi (2017) destacam alguns aspectos observados nos cursos de Licenciatura em Matemática analisados em sua pesquisa:

[...] o formato do curso voltado principalmente para uma matriz curricular tradicional; há um distanciamento entre a formação de professores de Matemática e as demandas da sociedade; as discussões voltaram-se para as perspectivas da Matemática pura e Matemática aplicada, que institucionalizadas, apontaram para uma postura mais convencional e menos para uma formação cidadã. (Somavilla; Bassoi, 2017, p. 106)

Já na perspectiva do acadêmico de licenciatura em matemática, Pereira e Curi (2012) relatam que

[...] é percebido nos cursos de licenciatura em matemática, características de um curso de bacharelado em matemática e uma desarticulação entre as

Tangram - Revista de Educação Matemática, Dourados - MS - v2 n. 1, pp. 102 - 121 (2018) 


\section{A Matemática financeira e Educação Financeira: impactos na formação inicial do professor}

próprias disciplinas do curso, com a prevalência das disciplinas do conhecimento específico de matemática. (Pereira; Curi, 2012, p. 123)

Ainda em tempo, quanto ao desenvolvimento dos tópicos de matemática financeira na licenciatura em matemática, consta em um relato: "Nós achamos que eles são importantes, pelo menos o pessoal da Educação Matemática acha que são importantes. Certos conteúdos...tratar certos conteúdos do Ensino Médio nesses momentos de Estágios ou coisas similares que a universidade desenvolve, porque o aluno... nem tudo ele sabe, ele vai ser professor e as vezes ele não domina o conhecimento, o conteúdo. Porque foi passado muito por cima na escolaridade dele na Educação Básica, então de certa forma tem que ser dado um tratamento de como trabalhar isso com o aluno dele." Nesse sentido, Pereira e Curi(2012, p.122) entendem que "Poucos são os cursos de Licenciatura em Matemática com uma formação completa em Educação Matemática e com experiências mais contextualizadas e significativas".

[...] os cursos de Licenciatura em Matemática tem a missão de formar professores, profissionais com formação sólida em conhecimentos matemáticos, mas também com competências de ensinar matemática na Educação Básica, ou seja, profissionais com uma formação pedagógica sólida e com conhecimentos específicos aprofundados, fazendo com que o futuro formando procure interrelacionar essas formações. (Pereira; Curi, 2012, p. 122)

Ainda que o docente entrevistado seja licenciado em Matemática e Pedagogia, e saliente o entendimento dos professores da Educação Matemática nessa perspectiva, considera que os conceitos de matemática financeira não precisam ser inseridos especificamente numa componente curricular, podendo ser trabalhados satisfatoriamente nos estágios e inseridos nas Metodologias de Ensino de Matemática.

Quanto a redução da carga horária anual da disciplina de Matemática Financeira foi $120 \mathrm{~h} / \mathrm{a}$ para $60 \mathrm{~h} / \mathrm{a}$, os entrevistados relatam que essa redução tem relação com o reconhecimento do curso de Licenciatura em Matemática, decisões colegiadas e com inserção de outras disciplinas também consideradas importantes para a formação de um professor de matemática. Num dos depoimentos o entrevistado explica porque a matemática financeira foi retirada da grade curricular em certo momento: "Agora como tem tópicos $e$ conteúdos para prosseguimento de estudos, quer dizer, uma preparação para o mestrado e doutorado, se aprofundou mais a Matemática das Ciências Exatas, tal como a matemática mais aplicada, uma matemática mais aprofundada porque...se achou na época que esses

Tangram - Revista de Educação Matemática, Dourados - MS - v2 n. 1, pp. 102 - 121 (2018) 


\section{A Matemática financeira e Educação Financeira: impactos na formação inicial do professor}

conteúdos... fica subentendido que o aluno já sabe da escolaridade básica." (19:20). Tal discurso se assemelha com o que Somavilla e Bassoi (2017) percebem em sua pesquisa:

[...] há o destaque da parte mais rica da Matemática Financeira ser a Álgebra, que está intrinsecamente ligada a Matemática pura. De outro modo, a Matemática aplicada às finanças é conhecida como Matemática Financeira. E pelo relato dos docentes, a Matemática Financeira sendo considerada como parte da Matemática aplicada, perderia espaço na grade curricular. Esse discurso reflete o cenário que se perpetua nos cursos de formação inicial de professores de matemática: um duelo entre os professores que defendem a Matemática aplicada e os que defendem a Matemática pura, colaborando para que em muitos cursos de Licenciatura em Matemática, a disciplina de Matemática Financeira fique no "limbo". (Somavilla; Bassoi, 2017, p. 80-81)

Diferentemente do explicitado acima, a Sociedade Brasileira de Matemática (SBM,

2013) sugere que a matemática financeira seja inserida no currículo da licenciatura.

[...] quando se considera que um dos objetivos da educação básica é a formação de um cidadão capacitado para integrar a sociedade com conhecimento necessário de matemática aplicada, requerido pelo mundo moderno, é imprescindível que o currículo de licenciatura contemple o conhecimento que prepare devidamente o futuro professor, colocando-o em contato com as aplicações da matemática mais relevantes para a humanidade... o tratamento matemático de problemas do mundo real, além de noções de matemática financeira que são fundamentais ao exercício de direitos do cidadão. (SBM, 2013, p. 31)

Por fim, com a inserção da Educação Financeira no Ensino Fundamental as competências necessárias para o bom desenvolvimento da temática no contexto escolar ainda precisam ser definidas. Assim, a luz da interrogação de pesquisa, na próxima categoria está exposto o que emergiu das unidades de significado destacadas nos documentos analisados, trazendo o olhar para a relação entre a Matemática Financeira e Educação Financeira.

\section{Categoria 2: Sobre a Matemática Financeira e a Educação Financeira}

A Educação Financeira não faz parte de nenhum Plano de Ensino analisado. Porém nos relatos dos docentes, emerge alguns pontos referentes à ela. Por exemplo, num dos depoimentos consta: “...a Matemática Financeira é a Matemática pela Matemática e a Educação Financeira é um pouco mais amplo.” (19:24). E ainda, para esse docente: “...você dá uma abrangência muito maior como Educação Financeira, um tratamento diferenciado de uma matemática pura, de uma matemática aplicada, de uma matemática apenas pela matemática."(19:24).

Tangram - Revista de Educação Matemática, Dourados - MS - v2 n. 1, pp. 102 - 121 (2018) 


\section{A Matemática financeira e Educação Financeira: impactos na formação inicial do professor}

Emerge também nos depoimentos: "A Educação Financeira eu acho que entra nessa questão que eu falei pra você de se trabalhar específico para a graduação e a Matemática Financeira mais específica para os cursos de Administração, Economia e Contábeis. Eu acho que têm que ter um diferencial, não os conteúdos, mas a forma de abordagem. Então eu acho que dentro do curso de Matemática poderia trabalhar, por exemplo, a Educação Financeira e a Matemática Financeira deixaria mais pros outros cursos. ” (20:12)

A breve descrição dessa categoria demonstra que os docentes dissociam as temáticas Educação Financeira e Matemática Financeira. Não consideram a possibilidade de desenvolver as temáticas paralelamente. Somavilla e Bassoi (2017) expõe em sua pesquisa a mesma visão observada nos relatos dos docentes.

Existe portanto, a divisão dos conteúdos relacionados à matemática pura como: porcentagem e juros, por exemplo, em uma disciplina nomeada Matemática Financeira e outra que contempla as aplicações desses conteúdos em uma disciplina nomeada Educação Financeira, como se essas tivessem em instâncias separadas. (Somavilla; Bassoi, 2017, p.9697)

Para Muniz (2010), os conceitos de Matemática Financeira são importantes para a formação de cidadão educado financeiramente. E salienta que a

[...] educação financeira está inexoravelmente relacionada à construção dessas competências, principalmente ao processo de construção da cidadania, pois na medida que aumenta a capacidade de análise em situações financeiras, como decidir entre comprar à vista ou a prazo, identificar descontos em sistemas de financiamento, estimar o crescimento do capital investido, dentre outros, o consumidor, tem condições mais efetivas de exercer seus direitos por saber a matemática envolvida nessas situações. (Muniz, 2010, p.04)

Nessa perspectiva, atenta-se para a homologação da Base Nacional Comum Curricular (BNCC) sobre a inserção obrigatória da Educação Financeira no Ensino Fundamental, ficando sua abordagem vinculada principalmente às Ciências da Natureza e Matemática. Especificamente na Matemática, a orientação é que os alunos desenvolvam conceitos básicos considerados de iniciação à educação financeira, tais como noções de finanças e economia.

Ao considerar que os licenciados em Matemática irão ministrar os conceitos básicos de educação financeira para os alunos do Ensino Fundamental, ressalta-se as relações entre a matemática da escola e a matemática do cotidiano. Hofmann e Moro (2012) reconhecem que a atividade econômica pode ser a mais recorrente das manifestações da matemática na

Tangram - Revista de Educação Matemática, Dourados - MS - v2 n. 1, pp. 102 - 121 (2018) 


\section{A Matemática financeira e Educação Financeira: impactos na formação inicial do professor}

atividade humana. As autoras defendem a consonância entre a Educação Matemática e a Educação Financeira

[...] sobretudo no esforço de (a) promover a aplicabilidade do conhecimento matemático escolar, garantindo-lhe a relevância, e (b) conferir significados econômicos aos problemas matemáticos e vice-versa, explorando bidirecionalmente a importância do contexto na construção de sentido e na solução de problemas. (Hofmann; Moro, 2012, p.47)

E ainda, para Ponte (2008) o significado da expressão "educação matemática"

[...] varia com o contexto onde é usada. Por um lado, a educação matemática constitui um campo de práticas sociais, cujo núcleo é a prática de ensino e de aprendizagem de professores e alunos, mas que incluiu igualmente outras vertentes como as práticas de apoio à aprendizagem extra-escolar e a produção de materiais didáticos. Por outro lado, a educação matemática constitui um campo de investigação acadêmica, onde se produz novo conhecimento sobre o que se passa no campo anterior. E, por outro lado ainda, é um campo de formação, onde se transmite esse conhecimento a novas gerações de professores e de investigadores e também aos professores em serviço. (Ponte, 2008, p. 1)

Nesse estudo, verifica-se a presença da disciplina de Matemática Financeira no curso de Licenciatura em Matemática da UNIOESTE/PR. Porém o que surge num dos relatos é que no Curso de Matemática, a Educação Financeira seria a melhor opção, o que coaduna com Fiorentini (2009), que sugere uma alternativa para fortalecer a formação do professor de Matemática: a projeção de uma aliança colaborativa entre universidade e escola básica. Ou seja, o ensino da Educação Financeira na formação inicial de um professor de matemática tendo em vista a necessidade exigida pela BNCC para o seu pleno desenvolvimento no Ensino Fundamental.

Já quanto a Matemática Financeira, o docente expõe em seu depoimento que poderia ser trabalhada nos cursos de Administração, Ciências Contábeis e Ciências Econômicas. Essa posição pode ter haver com as discussões recentes sobre a literacia financeira dos cidadãos, pois evidencia-se uma contradição na oferta da disciplina de Matemática Financeira no período de 1989 à 2017, no curso de Licenciatura em Matemática, tendo uma proposta que mais se ajusta aos cursos citados anteriormente pelo docente.

Nessa perspectiva, Mota (2016) apresenta um estudo sobre o nível de literacia financeira dos professores do ensino fundamental e médio, realizado nas escolas municipais do município de Sorocaba. O autor confirma a importância dada ao tema pelos participantes da pesquisa, pois no primeiro questionário aplicado aos mesmos, 93\% deles acreditam na possibilidade do ensino de finanças pessoais em sua disciplina. Em contrapartida, no

Tangram - Revista de Educação Matemática, Dourados - MS - v2 n. 1, pp. 102 - 121 (2018) 


\section{A Matemática financeira e Educação Financeira: impactos na formação inicial do professor}

segundo questionário, evidenciou-se a falta de clareza para os participantes sobre o que é comportamento, conhecimento e atitude financeira. E destaca que nessas três dimensões analisadas:

Os resultados apontam um distanciamento entre os resultados, haja vista que no grupo conhecimento $95 \%$ da amostra possui baixa literacia financeira, e nas demais dimensões mais de $40 \%$ possuem baixa literacia financeira [...] (Mota, 2016, p. 87)

Uma das propostas de Mota (2016, p. 88) é quanto a formação dos professores relativo ao tema, sendo que

[...] deve propor conteúdos e aspectos didáticos para que esse professor possa transmitir aos seus alunos uma educação financeira de qualidade e que esses ensinamentos sejam práticos, atrativos e se tornem importantes para suas decisões financeiras futuras.

E ainda o autor sugere a ação: "Cursos sobre matemática financeira básica e avançada, visando a elucidar ao professor a necessidade de conhecimentos conceituais sobre juros, simples, compostos, conceitos de inflação, valor do dinheiro no tempo [...] (Mota, 2016, p. 88)

Dessa forma, utilizam-se no estudo citado pelo autor tanto os conhecimentos de Educação Financeira e Matemática Financeira, sugerindo assim, que para alcançar o nível de literacia financeira satisfatória seria necessário alcançar as competências de ambas as temáticas. Silva e Selva (2018) também expõem sua pesquisa nessa perspectiva.

[...] percebe-se que as atividades de educação financeira, propostas no livro do aluno, podem proporcionar contextualização do ensino de matemática e sugerem, na maioria dos casos, que o trabalho se dê a partir da realidade dos alunos, mas torna-se necessário que as orientações sejam mais específicas, no que diz respeito aos conhecimentos matemáticos, para auxiliar os professores com o trabalho em sala de aula. (Silva; Selva, 2018, p.140)

Com efeito, o que se observou nesse estudo é que as opiniões dos docentes divergem quanto ao ensino da Educação Financeira e da Matemática Financeira na formação de um professor de Matemática. Essa visão não parece estar relacionada com o oferta ou não da disciplina no curso de Licenciatura em Matemática, mas com uma concepção individual do docente ministrante da disciplina sobre o que é mais relevante na formação de professores de Matemática. Numa das falas explicita essa observação: “...quando eu fui coordenador do curso de Matemática uma das disciplinas que nós implantamos foi a Matemática Financeira." (20:4)

Tangram - Revista de Educação Matemática, Dourados - MS - v2 n. 1, pp. 102 - 121 (2018) 


\section{A Matemática financeira e Educação Financeira: impactos na formação inicial do}

professor

E o professor complementa: “...Qualquer lugar que você vá, qualquer mercado, qualquer banco, qualquer lugar que você vá, qualquer loja... Matemática Financeira tá presente. E isso infelizmente não está mais sendo trabalhado na universidade, então que tipo de professor que está se formando hoje?” (20:7). Para as autoras Somavilla e Bassoi (2017)

[...] a articulação entre as políticas públicas - formação inicial de professores de matemática - educação básica ainda não se consolidou na perspectiva da contribuição da matemática para a cidadania, indica-se como um dos desafios atuais a ser considerado: uma formação financeira em todos os níveis de ensino. (SOMAVILLA; BASSOI, 2017, p. 107)

Por fim, as discussões sobre a literacia financeira dos professores de Matemática e dos cidadãos em geral estão em pauta nos diversos níveis de ensino. Assim, não esgotam-se as análises, mas espera-se colaborar também para um repensar nessa perspectiva.

\section{CONSIDERAÇÕES FINAIS}

A promoção de uma formação financeira dos cidadãos é uma pauta reconhecida internacionalmente. No Brasil, os debates na área educacional nessa perspectiva ainda não tem muita expressão. $\mathrm{O}$ cenário que emergiu nessa pesquisa explicita alguns pontos que são comuns a muitos cursos de formação inicial de professores de Matemática: o distanciamento entre o ensino de matemática financeira e a formação financeira necessária aos cidadãos; os planos de ensino da disciplina de matemática financeira convencionais mantendo praticamente a mesma ementa, mesmas referências bibliográficas e muitas vezes os mesmos objetivos utilizados por outros cursos, tais como: Administração, Ciências Contábeis e Ciências Econômicas, e ainda o entendimento dos docentes entrevistados sobre a dissociação entre a matemática financeira e educação financeira.

Um ponto observado tanto nos planos de ensino quanto nos relatos dos docentes é sobre não existir uma referência bibliográfica de matemática financeira voltada para os cursos de Licenciatura em Matemática. Nesse sentido, a identidade dessa disciplina para a formação de um professor de matemática não se consolida, mantendo as mesmas características de outros cursos há décadas. Ainda em tempo, atenta-se para as posições individuais dos docentes sobre a importância ou não da inserção da disciplina de matemática financeira no curso de Licenciatura em Matemática. Isso sinaliza para ausência de discussões

Tangram - Revista de Educação Matemática, Dourados - MS - v2 n. 1, pp. 102 - 121 (2018) 


\section{A Matemática financeira e Educação Financeira: impactos na formação inicial do professor}

coletivas e mais posturas individuais quanto às decisões colegiadas no curso de Licenciatura em Matemática em questão.

Outro aspecto a se destacar é a dissociação entre a Matemática Financeira e Educação Financeira pelos sujeitos da pesquisa. Confinaram a Educação Financeira numa perspectiva da formação do professor de matemática e não relataram que ele era importante na condução da Matemática Financeira nos outros cursos, uma vez que todos os cursos declarado ou não em seus projetos pedagógicos, pretendem formar cidadãos participativos na sociedade.

Por fim, na perspectiva fenomenológica as manifestações do fenômeno se esgotam. Alguns aspectos percebidos pelos pesquisadores mostram que existe muito ainda o que se fazer na formação inicial de um professor de Matemática, levando-se em conta a Matemática Financeira e Educação Financeira, que resulte em domínio técnico e educacional no Ensino Básico.

\section{Referências}

Almeida, Rodrigo Martins de; Junior, Marco Aurelio Kistemann. (2015) O Movimento das Pesquisas em Educação Matemática Financeira Escolar 1999 a 2015. Programa de Pós Graduação em Educação Matemática- UFJF. Disponível em: <http://www.ufjf.br/mestradoedumat/files/2011/09/Produto-educacionalRodrigo.pdf> . Acesso em: 25/11/2016.

Andretti, Evandro Carlos. (2017) As contribuições do Pibid/Unioeste na formação de professores: subprojetos de matemática de Cascavel e Foz do Iguaçu. 2017. $128 \mathrm{f}$. Dissertação (Mestrado) - Curso de Mestrado em Ensino, Universidade Estadual do Oeste do Paraná, Foz do Iguaçu, 2017.

Brasil. (2017) Banco Central do Brasil. Série Cidadania Financeira: estudos sobre educação, proteção e inclusão / Banco Central do Brasil - 5. ed. - Brasília : Banco Central do Brasil. Nota: n. 5. Competências em educação financeira: descrição de resultados da pesquisa da Rede Internacional de Educação Financeira adaptada e aplicada no Brasil.

<http://www.bcb.gov.br/nor/relincfin/serie_cidadania_financeira_pesquisa_infe_br_ \%200443_2017.pdf>. Acesso em : 10 jan. 2018

Brasil. (1998) Parâmetros Curriculares Nacionais, terceiro e quarto ciclos do ensino fundamental. Introdução aos Parâmetros Curriculares nacionais. Brasília, MEC/SEF. Disponível em: <http://portal.mec.gov.br/seb/arquivos/pdf/introducao.pdf>. Acesso em: 17/07/2016.

Cidadania financeira. (2017) Educação, proteção e inclusão financeira da população brasileira.

Disponível em:

Tangram - Revista de Educação Matemática, Dourados - MS - v2 n. 1, pp. 102 - 121 (2018) 


\section{A Matemática financeira e Educação Financeira: impactos na formação inicial do professor}

$\langle$ http://www.bcb.gov.br/pre/pef/port/programa_cidadania_financeira.pdf $>$. Acesso em 17 nov.

Fiorentini, Dario. (2008) A Pesquisa e as Práticas de Formação de Professores de Matemática em face das Políticas Públicas no Brasil. Bolema: Boletim de Educação Matemática, Rio Claro, v. 21, n. 29, p.43-70. Disponível em: <http://www.periodicos.rc.biblioteca.unesp.br/index.php/bolema/article/viewFile/171 8/1495>. Acesso em: 30 de maio 2016.

Fiorentini, Dario. (2009) Educação Matemática: diálogos entre a universidade e a escola. In: ENCONTRO GAÚCHO DE EDUCAÇÃO MATEMÁTICA, 10., 2009, Ijuí. Anais... - Ijuí: UnijuÍ, . p. 1 - 20. Disponível em: <http://www.projetos.unijui.edu.br/matematica/cd_egem/fscommand/CO/CO1.pdf >. Acesso em: 23 de maio 2016.

Hofman, R. M, Moro, M.L.F.(2012) Educação matemática e educação financeira: perspectivas para a ENEF. Zetetiké - FE/Unicamp - v. 20, n. 38 - jul/dez . Disponível em: < file:///C:/Users/adria/Downloads/8646609-20690-1-PB.pdf>. Acesso em 02 jun. 2018.

Lorenzato, Sérgio; Fiorentini, Dario.(2001) O profissional em Educação Matemática. Santos: UNISANTA. Disponível em: <http://sites.unisanta.br/teiadosaber/apostila/matematica>. Acesso em: 12 de out. 2015

Manzini, E. J. (2007) Considerações sobre a transcrição de entrevistas. In: Manzini, E. J. A entrevista como instrumento de pesquisa em Educação e Educação Especial: uso e processo de análise. Marília, SP: UNESP, p. 1-17. 2007. Disponível em: <http://www.oneesp.ufscar.br/texto_orientacao_transcricao_entrevista $>$. Acesso em: $17 / 05 / 2016$

Martins, J. \& Bicudo, M.A.V. (1989)A Pesquisa Qualitativa em Psicologia: fundamentos e recursos básicos. São Paulo: Moraes/ EDUC.

Milone, Giuseppe. (2006) Matemática financeira. São Paulo: Thomson Learning.

Mota, Marcelo Nunes.(2016) Literácia financeira de educadores : um estudo na rede pública do município de Sorocaba. 98 f. Dissertação (Controladoria Empresarial) Universidade Presbiteriana Mackenzie, São Paulo. Disponível em: < http://tede.mackenzie.com.br/jspui/handle/tede/3166> . Acesso em 15 jan 2018.

Muniz, I. Jr. (2010) Educação Financeira: Conceitos e Contextos para o Ensino Médio. In: $X$ Encontro Nacional de Educação Matemática - X ENEM, 2010, Salvador. X ENCONTRO NACIONAL DE EDUCAÇÃO MATEMÁTICA, 2010.

Mutti, G. S. L.; Somavilla, Adriana Stefanello . Postura fenomenológica de investigação: relatando experiências de pesquisa no contexto da Educação Matemática. In: II Semana Acadêmica da Licenciatura em Matemática - II SALIMAT, 2017, Foz do Iguaçu. Anais de Resumos - II Semana Acadêmica da Licenciatura em Matemática, 2017. v. 1. p. 1417.

Tangram - Revista de Educação Matemática, Dourados - MS - v2 n. 1, pp. 102 - 121 (2018) 
Paraná. Secretaria de Estado da Educação. (2008) Secretaria de Estado da Educação. Diretrizes Curriculares da Educação Básica - Matemática. Curitiba:. Disponível em: <http://www.educadores.diaadia.pr.gov.br/arquivos/File/diretrizes/dce_mat.pdf $>$.

Acesso em 16/08/2016.

Pereira, Maria Neusa de Lima; Curi, Edda. (2012)Formação de professores de matemática sob o ponto de vista de alunos formandos. REnCiMa, v. 3, n. 2, p. 116-124, jul/dez. Disponível em: http://revistapos.cruzeirodosul.edu.br/index.php/rencima/article/view/112/74>. Acesso em 01 jun 2018.

Pimenta, Selma Garrido; Lima, Maria Socorro Lucena. (2004)Estágio e Docência. São Paulo: Cortez.

Ponte, João Pedro da. (2002) A vertente profissional da formação inicial de professores de matemática. In: Educação Matemática em Revista, n. 11 A. p. 3-8.

Ponte, João Pedro da.(2008) A investigação em educação matemática em Portugal: Realizações e perspectivas. In. Luengo-gonzález, R. et. al. (Ed.), Investigación en educación matemática. Badajoz: SEIEM, 2008. p. 55-78

Sbem. (2013) A formação do professor de matemática no curso de licenciatura: reflexões produzidas pela comissão paritária SBEM/SBM. Brasília: Sociedade Brasileira de Educação Matemática, Boletim Sbem, n. 21, p. 1-42, fev. Disponível em: <http://www.sbembrasil.org.br/files/Boletim21.pdf>. Acesso em 05/01/2017.

Silva, a. M, Powell; A. B. (2013) Um programa de Educação Financeira para a Matemática Escolar da Educação Básica. XI Encontro Nacional de Educação Matemática: Retrospectiva e Perspectiva. Curitiba, Paraná.

Silva, Inglid Teixeira; Selva, Ana Coelho Vieira.(2018) Programa de educação financeira nas escolas - ensino médio: uma análise das orientações contidas nos livros do professor e suas relações com a matemática. REnCiMa, v. 9, n. 1, p. 140-157. Disponível em:

http://revistapos.cruzeirodosul.edu.br/index.php/rencima/article/view/1293/953> . Acesso em 02 jun 2018.

Somavilla, Adriana Stefanello. (2017) A inserção da disciplina de Matemática Financeira nos cursos de Licenciatura em Matemática dos Institutos Federais de Educação, Ciência e Tecnologia da Região Sul do Brasil. 2017. Dissertação- Universidade Estadual do Oeste do Paraná, Foz do Iguaçu, 2017.

Somavilla, Adriana Stefanello; Bassoi, Tania Stella. (2017) A matemática financeira nos cursos de licenciatura em matemática. Saarbrücken, Alemanha: Novas Edições Acadêmicas, v.1. p.128. ISBN: 9783330996229.

Enviado:30/09/2018

Aceito: $12 / 12 / 2018$

Tangram - Revista de Educação Matemática, Dourados - MS - v2 n. 1, pp. 102 - 121 (2018) 